\title{
CHANGES IN PHYSICAL PROPERTIES OF A TYPIC HAPLOCAMBID BY ANNUAL CROP CULTURE
}

\author{
O. Seguel ${ }^{1}$, C. Baginsky ${ }^{1}$, A. Contreras ${ }^{1}$, J. Covarrubias ${ }^{1}$, C. González ${ }^{1}$, and \\ M. Sandoval ${ }^{1}$ \\ ${ }^{1}$ Universidad de Chile, Facultad de Ciencias Agronómicas. Santa Rosa 11315. La Pintana, \\ Santiago. Casilla 1004. *Corresponding author: oseguel@uchile.cl
}

\begin{abstract}
As an alternative to organic soil amendments used in the Copiapó Valley (northern Chile), this study analyzed the magnitude of changes in physical soil properties associated with different crop rotations on the rows on a grape orchard. The study was performed in the locality of Los Loros, Atacama Region, during the 2006-2008 seasons. In a Typic Haplocambid soil (2-5\% slope, coarse loam) with a 6-year old grape plantation, a control and three crop rotations were established, each with four replicates. Soil samples were taken at three depths $(0-10 ; 10-40 ; 40-60 \mathrm{~cm})$, evaluating bulk density, penetration resistance, aggregate stability, pore size distribution and air and water flux. Crop rotation did not produce statistical differences in soil density compared with the control treatment; nevertheless, soil mechanical strength decreased compared to the control without crops. Aggregate stability increased on the surface horizon when Poaceae and Fabaceae were used separately, but not when they were planted together. Below the surface this effect vanished and no significant differences were observed compared with the control. The leguminous crops promoted a more continuous porous system, with an increase of coarse porosity and a higher air and water flux capability. A longer time period of crop rotation is required to improve the productive potential of grapes.
\end{abstract}

Keywords: Porosity, aggregate stability, mechanical strength, productivity.

\section{INTRODUCTION}

Soil as a dynamic system is characterized by many properties, among which the physical properties are relevant for their effects on the dynamic conditions of the system, changing the conductive properties and storage capacity of soils (Benavides, 1992). This suggests that soil properties, including structure, play a fundamental role in defining the parameters of the agricultural capacity of a soil.

Pagliai and Vignozzi (2002), defined soil structure as the natural organization of individual particles into large units known as secondary units or peds, which, when properly arranged, create favorable conditions of soil aeration and moisture (Salgado, 1999).

A degradation of the soil structure causes changes in both pore size distribution and bulk density, affecting plant development by altering the soil-water-plant interaction necessary for the exchange of elements between the plant and its environment (Ellies et al., 1993). 
Adequate levels of organic matter in soil promote the formation of structural macropores, allowing adequate air and water conductivity (Brady and Weil, 2000) as well as increased water retention in the soil (Hudson, 1994). For soils with low content of organic matter and coarse texture, an external supply of organic amendments is advisable to produce physical and chemical changes in soil (Seguel et al., 2003), thus promoting adequate growth of crops.

A project attempting to ameliorate the problems of soil degradation in the Region of Atacama was begun in 2006, focused on improving the physical properties of soil through organic matter management to enhance production of table grapes (Vitis vinifera), which is the dominant crop in the area. The Copiapó Valley has exceptional climatic conditions for this crop (Lobato and Valenzuela, 2000), but there are serious problems of accumulation of soluble salts on the soil surface caused by capillary rise, leading to salinization and deterioration of soil structure (Sierra et al., 2001).

In order to mitigate soil salinization, farmers of the region have implemented different strategies, which include establishing plants on ridges and high rates of irrigation applied to flush salts by deep percolation. However, repeated traffic of machinery and human trampling of the ridge in inappropriate water conditions produce a deterioration of the structure that increases over time.

Since one of the main constraints in the Copiapó Valley for the cultivation of grapes is the quality of the soil, implementing soil management to rebuild and strengthen the stability of aggregates, improving both the structure and the pore size distribution should have a positive effect on crop yield. In this study we postulated that establishing annual crop rotations between the rows in coarse textured soils will increment water holding capacity and aggregate stability, because of the constant input of organic matter due to the growth and annual renewal of roots.

Among the annual species with most potential for this purpose are members of the families Fabaceae and Poaceae. According to Ruiz (1996), Fabaceae are characterized by having a pivotal taproot, which is associated with the ability to resist drought; in species such as broad bean the taproot is very vigorous and may reach over a meter deep in soil without limitations. Another attribute is their ability to form a symbiotic association with Rhizobium, through which they receive atmospherically fixed nitrogen (Sprent and Minchin, 1985), making them suitable for degraded soils or those with low levels of this nutrient. On the other hand, Poaceae are characterized by a fasciculate root system, which, according to Faiguenbaum (2003), is developed in the first $30 \mathrm{~cm}$ depth, and may reach about $60 \%$ of the total dry weight of the plant. Within this family, there are species with greater tolerance to drought (sorghum, maize) that have a large number of roots that go much deeper.

The objective of this study was to determine the relationship between the type of crop rotation established on the rows of a grape vine growing and the magnitude of change in soil physical properties, and their effect on the productive capacity of the vines.

\section{MATERIALS AND METHODS}

\section{Study site}

The study was conducted from 2006 to 2009 in a farm located in the town of Los Loros, Copiapó, Atacama Region (27 49'53" S - 70 06'54" W). The soil belongs to the Elisa de Bordós Series 
(Typic Haplocambid); it consists of alluvial-colluvial sediments, resulting in a thin soil with a substratum of faceted gravel and pebbles, with andesitic and dioritic composition. The textural class is sandy loam and the proportion of stone in deep is greater than 50\% (MINAGRI, 1968). It is a well drained soil with high permeability; the slope varies mainly from 0.7 to $2.0 \%$, although somewhat greater in a few places. Historically, the site has received applications of organic amendments in the form of goat manure, in doses of $10 \mathrm{Mg} \mathrm{ha}^{-1} \mathrm{yr}^{-1}$; thus, we performed a baseline general soil chemical characterization evaluating macronutrient, electrical conductivity, sodium and boron. With regard to climate, the town of Los Loros has a Transitional Desert Climate (BWI; Juliá et al., 2008), which is characterized by low winter precipitation ranging between 25 and $50 \mathrm{~mm}$ per year, with daily average temperatures fluctuating between $19^{\circ} \mathrm{C}$ in summer and $11^{\circ} \mathrm{C}$ in winter.
Soil samples were taken from pedogenetic horizons in October 2008 and analyzed at the Laboratory of Soil Physics, Department of Soil Engineering at the Faculty of Agricultural Sciences, University of Chile.

\section{Treatments and experimental design}

We selected an area with low vegetative growth of the vines due to soil restrictions. The soil was characterized morphologically (2006) in pits arranged randomly to verify the homogeneity of the site. Sixteen plots were located and grouped into four complete randomized blocks, with four treatments and four replicates. The experimental unit was a plot of $10 \mathrm{~m}$ long by $1 \mathrm{~m}$ wide, containing 4 vines with their respective ridge. For the soil/plant measurements, only the two central plants and their associated soil were considered within each experimental unit. Treatments for the three rotation systems and the control without crop are presented in Table 1.

Table 1. Control treatment and crop rotations on grape rows during the 2006 to 2008 seasons.

\begin{tabular}{cccc}
\hline \multirow{2}{*}{ Treatment } & \multicolumn{3}{c}{ Years and crops } \\
\cline { 2 - 4 } & 2006 & 2007 & 2008 \\
\hline T1 & Control & Control & Control \\
T2 & Maize + broad bean & Maize + pea & Barley \\
T3 & Pea & Sorghum & Broad bean \\
T4 & Broad bean & Barley & Pea \\
\hline
\end{tabular}

\section{Crop management}

The grape orchard, Vitis vinifera cv. Thompson Seedless (own-rooted vine) was established in 2001 on a median (ridge) $10 \mathrm{~cm}$ high and $1 \mathrm{~m}$ wide and trained as an overhead trellised system. A drip irrigation system was established at the beginning; management of the vines in terms of fertilization, irrigation, pruning and harvesting was common to all treatments. At the end of the study, 
pruning mass $\left(\mathrm{kg} \mathrm{ha}^{-1}\right)$ and commercial grape production $\left(\mathrm{kg} \mathrm{ha}^{-1}\right)$ were measured.

Crops used in the rotations were: broad bean (Vicia faba) Aguadulce variety; maize (Zea mays) San Pablo hybrid; barley (Hordeum vulgare) Aurora variety; pea (Pisum sativum) Luanco variety and sorghum (Sorghum vulgare $\mathrm{x}$ sudangrass) Sordán 79 variety. Sowing was done by hand, placing the seed in open furrows on the ridge after 8 hours of irrigation. In the case of legumes, a commercial inoculant of Rhizobium leguminosarum bv. viciae was used. The planting distance on the row was 15,10 and $5 \mathrm{~cm}$ for maize, broad bean and pea, respectively, while barley and sorghum were sown in a continuous stream (320 $\left.\mathrm{kg} \mathrm{ha} \mathrm{h}^{-1}\right)$. During the 2006 season, T2 (maize + broad bean) corresponded to maize in summer and broad bean in autumn, while in the 2007 season (maize + pea) both crops were established at the same time, in alternate rows. Each crop was established on a total of five rows, spaced at $15 \mathrm{~cm}$ (barley, sorghum, pea) and $25 \mathrm{~cm}$ (maize, broad bean). Sowing was done in January of each season (summer), except for broad bean in 2007, which was sown in July. Crops were allowed to develop until the application of a sprouting controller (hydrogen cyanamide) in June, at which time they were harvested, chopped and distributed over the ridge. Broad bean on 2007 was chopped on September.

Fertilization and irrigation performed based on the needs of the vine, with the normal program used by farmer, especially with regard to drip irrigation.

\section{Measured soil properties}

From pits dug between the two central plants of each experimental unit on the ridge, soil samples were taken (October 2008) at three depths: $0-10 \mathrm{~cm}, 10-40 \mathrm{~cm}$ and 40-60 $\mathrm{cm}$, coinciding with the ridge and the soil horizons. With a total of 48 soil samples (4 treatments, 4 replicates, 3 depths) we performed the following measurements:

\section{Bulk density (Db), penetration resistance and aggregate stability}

$\mathrm{Db}$ was determined by the core and clod methods (Grossman and Reinsch, 2002); in the first case cylinders of $5.9 \mathrm{~cm}$ in diameter and $5 \mathrm{~cm}$ in height were used, while in clod method, three samples were taken (clods) at two depths (0-10 cm and $10-40 \mathrm{~cm})$ in each experimental unit. No samples were taken at greater depth due to the instability of the aggregates.

To evaluate the resistance to penetration, a digital effort meter (EXTECH, model 475044) was used, with a $30^{\circ}$ cone $0.7 \mathrm{~cm}$ in diameter. Vertical and horizontal measurements were taken (10 replicates each) at the three depths mentioned above. To homogenize water content a pit was dug 24 hours after irrigation, taking the measurements as digging progressed. The evaluations were carried out below the drip zone of the irrigation system.

Macro-aggregate stability to water, measured as the variation in diameter of dry and wet sieving (Hartge and Horn, 1992) was evaluated in the first two horizons $(0-10$ and $10-40 \mathrm{~cm})$. From the sieving curves, the cumulative mass fractions of aggregates were plotted, determining the aggregate stability by measuring the relative change in diameter of the aggregates at $90 \%$ of the cumulative fraction based on mass for each screening (dry and wet).

The stability of micro-aggregates was assessed by calculating the dispersion rate (DR) described by Berryman et al. (1982). Aggregates with diameters between 1 and $2 \mathrm{~mm}$, selected by sieving, 
were subjected to dispersion with distilled water, while a counter sample was completely dispersed with a solution of sodium pyrophosphate $(0.5 \mathrm{~N})$ and mechanical agitation for 10 minutes. In both suspensions the silt and clay content were determined, calculating the aggregate stability as the ratio of (clay + silt) from dispersion in distilled water and (clay + silt) from chemical and mechanical dispersion (Seguel et al., 2003).

\section{Characterization and functionality of the pore system}

The distribution of pore sizes was determined by measuring the volumetric water content of soil at different tensions, which is equivalent to the volume of pores saturated by the volume of water. We measured the water retention of undisturbed soil samples, subjecting them to 6 kiloPascals $(\mathrm{kPa})$ in a sand box and 33 and $1,500 \mathrm{kPa}$ in a pressure plate (Klute, 1986). In this way, it was possible to characterize the fast drainage pores (FDP) as the difference between total porosity and the equilibrium at -6 $\mathrm{kPa}$, slow drainage pores (SDP) as the difference between water content at -6 and $-33 \mathrm{kPa}$, and useful water availability (WA) calculated as the difference between water retention at -33 and -1500 $\mathrm{kPa}$.

With the same samples used to determine the water retention curve, the airflow was measured according to Peth (2004) at two water tensions (-6 and -33 $\mathrm{kPa})$. In addition, the field saturated hydraulic conductivity was determined using the cylinder infiltrometer method (Reynolds et al., 2002). Metal cylinders $30 \mathrm{~cm}$ in diameter and $40 \mathrm{~cm}$ in height were used, installed between the two central plants of each experimental plot.

\section{Statistical analysis}

In order to evaluate the variables, an analysis of variance (ANOVA) was performed, comparing treatments at the same depth. When significant differences were found, a multiple range test was used (Tukey, $p \leq 0.05$ ).

\section{RESULTS AND DISCUSSION}

\section{General properties}

Laboratory tests performed in 2006 showed that in the case of macronutrients, total $\mathrm{N}$ concentrations ranged between $0.16 \%$ and $0.19 \%$, values considered as low according to the literature. This contrasted with $\mathrm{P}$ and $\mathrm{K}$, whose values were within the range of high availability. Although it is not a sodic soil (4.4\% $\mathrm{Na}$ saturation), the first $30 \mathrm{~cm}$ depth presented relatively high values of exchangeable $\mathrm{Na}\left(0.6 \mathrm{cmol} \mathrm{kg} \mathrm{kg}^{-1}\right)$ and EC (3.6 dS m $\left.\mathrm{m}^{-1}\right)$, which obliges the use of tolerant crops to such conditions. Finally, boron was within normal ranges.

\section{Soil physical properties}

\section{Bulk density}

Among the physical properties of soil, $\mathrm{Db}$ is one of the most susceptible to changes resulting from poor farming practices (Horn et al., 1994). Its value, linking soil mass to its volume, allows detection of changes in total porosity, because the solid fraction of soil is incompressible. The results of the $\mathrm{Db}$ analysis are presented in Figure 1. 


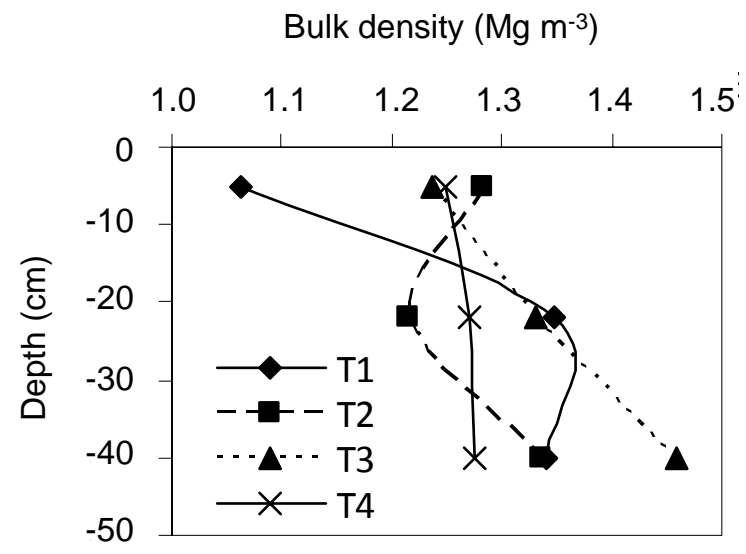

Figure 1. Bulk density $\left(\mathrm{Mg} \mathrm{m}^{-3}\right)$ by the core method as a function of depth for each treatment.

\begin{abstract}
According to Sommer (1979), anthropogenic consolidation is generated mainly by the traffic of machinery, trampling and soil tillage in inappropriate conditions, whose magnitude depends on the intensity, timing and frequency of the load on the ground. In this study, the treatments showed statistically no significant difference, which suggests that there was no major change in the total porosity development by growing annual crops compared to the control. The control had a low Db at the surface $(0-10 \mathrm{~cm})$, because of organic amendments additions and chisel scarification on the surface as common practices, which were continued to maintain the current management of the producer. However, the control (T1) had a rather large range of variation of $\mathrm{Db}$ in the profile with a tendency to increase at greater depths; similar to the results for $\mathrm{T} 3$, the rotation in which legumes were
\end{abstract}

most prevalent. This result contrasts with $\mathrm{T} 2$ and $\mathrm{T} 4$, where $\mathrm{Db}$ remained fairly uniform at different depths and in T2 it even had a tendency to decrease at $25 \mathrm{~cm}$ deep. The difference between the control and $\mathrm{T} 2$ and $\mathrm{T} 4$ can be attributed to the root growth of the annual crops; it may be due to the kind of the root system of each of the cultures used and to the combined effect of their rotation overtime (Fainguenbaum, 2003).

The values of $\mathrm{Db}$ determined by the clod method were all treatments in a narrow range (1.48 to $1.55 \mathrm{Mg} \mathrm{m}^{-3}$; Figure 2); no statistically significant differences were found between treatments at any depth. It is usual to obtain higher values with the clod method than with the core method, because inter-aggregate porosity is not included in the former (Brady and Weil, 2000). Even though these results allow us to infer that the roots of the crops had no 


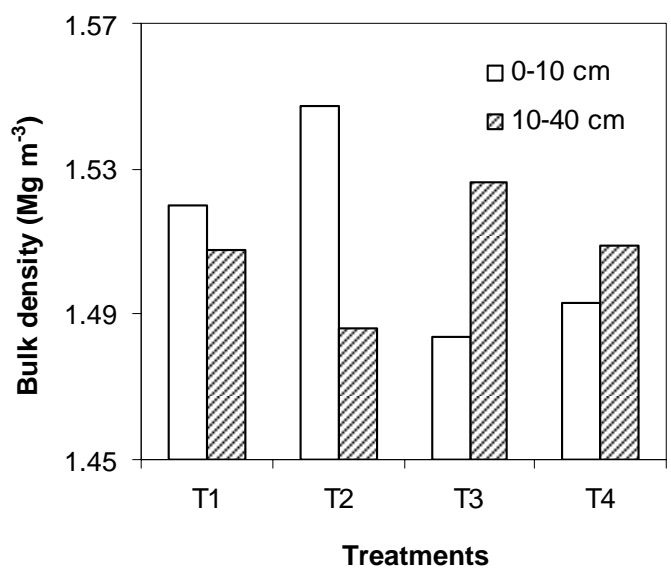

Figure 2. Bulk density $\left(\mathrm{Mg} \mathrm{m}^{-3}\right)$ by the clod method at $0-10 \mathrm{~cm}$ and $10-40 \mathrm{~cm}$ depth.

significant effect on the development of porosity within the aggregates, it should be noted that the relationship [1 - $\left(\mathrm{Db}_{\text {clod }}\right.$ $\left.\left./ \mathrm{Db}_{\text {core }}\right)\right]$ as an index of inter-aggregate pores (Seguel and Horn, 2006) yielded values in the zone of maximum rooting $(10-40 \mathrm{~cm})$ of 18,13 and $16 \%$ coarse pores for treatments $\mathrm{T} 2, \mathrm{~T} 3$ and $\mathrm{T} 4$, respectively, compared with $11 \%$ in the control.

\section{Penetration strength}

The resistance to penetration relates the effort which the roots in the soil need to exert to break through in the profile. High levels of strength denote compaction problems, which in some cases can become so intense that it impedes root growth (Lindstrom and Voorhees, 1994). Figure 3 shows the curves of penetration strength, vertical and horizontal, for each treatment. Measurements were made 24 hours after irrigation, immediately below the projection of the drip.
There were no significant differences between treatments because of the high variability of the results; however, there was a clear trend towards differentiation between the control (T1) and other treatments in both the vertical and horizontal axes.

Although the control had an application of organic amendment, its values of penetration resistance were always greater than those in the other treatments. The values reached by the control were mostly greater than 2.0 MPa, which, according to Threadgill (1982), implies a limitation for radial root growth. This would indicate that crop rotations are promoting a beneficial effect on the penetration resistance of soil, caused by the looseness of the soil aggregates as a product of root growth.

Finally, the similarity of values shown by crop treatments suggests that any of the three rotations is equally effective in the control of compaction, and the alternation between legumes and grasses (and thus different root patterns) is complementary and optimizes the effect. 
Vertical strength (MPa)

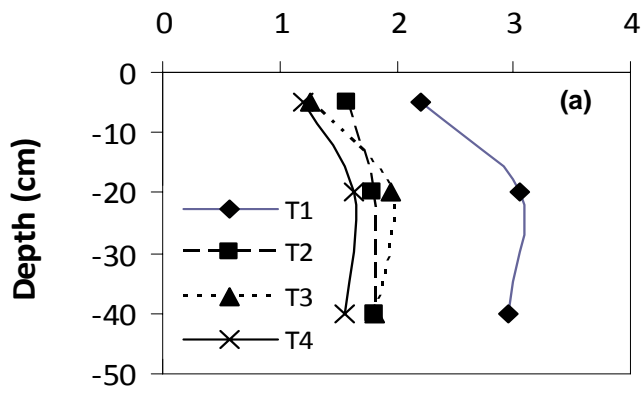

Horizontal strength (MPa)

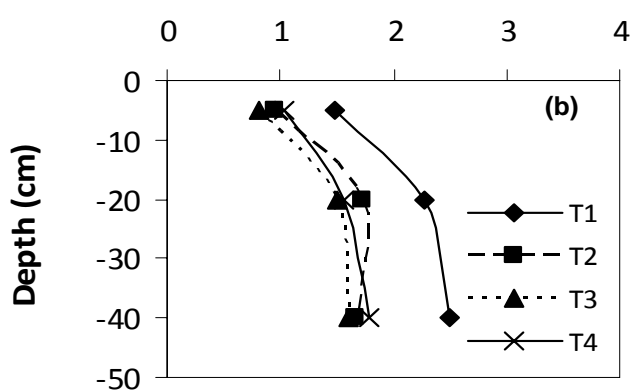

Figure 3. Penetration resistance $(\mathrm{MPa})$ as a function of depth. Vertical (a) and horizontal (b) values measured one day after irrigation.

\section{Aggregate stability}

The results of macro-aggregate stability against the wetting process are presented in Table 2.

Table 2. Aggregate stability evaluated as percentage variation of dry and wet diameter. Lower values indicate greater stability. Average ( \pm SD).

\begin{tabular}{ccc}
\hline \multirow{2}{*}{ Treatment } & \multicolumn{2}{c}{ Variation in diameter (\%) } \\
\cline { 2 - 3 } & $0-10 \mathrm{~cm}$ & $10-40 \mathrm{~cm}$ \\
\hline T1 & $60,6( \pm 15,5)$ & $73,7( \pm 15,1)$ \\
T2 & $78,2( \pm 9,2)$ & $76,6( \pm 5,7)$ \\
T3 & $35,4( \pm 28,1)$ & $60,5( \pm 19,6)$ \\
T4 & $51,9( \pm 32,2)$ & $66,3( \pm 11,7)$ \\
\hline
\end{tabular}

There is a general agreement that aggregate stability is strongly related to both the soil organic matter content (Chaney and Swift, 1984) and the activity of mesofauna and root development (Oades, 1993). This is because the roots, growing both in diameter and length, generate coarse porosity, which together with organic substances released from the rhizosphere lead to a pore that has a much greater stability when roots die compared with one formed without the intervention of radical growth (Kay, 1990).

Statistical analysis showed no significant differences between treatments; although certain trends can be seen, it is not possible to draw valid conclusions from them, since in most cases the cumulative fraction of $90 \%$ did 
not exceed an average aggregate size of $5 \mathrm{~mm}$ diameter for dry sieving. This demonstrates the instability of the macro-aggregates in this soil, which is expected considering the coarse texture and high gravel content. Nevertheless, at both depths, T3 and T4 showed a tendency to greater stability than the control.
To estimate the stability of micro aggregates (1-2 $\mathrm{mm})$ we used the dispersion ratio (DR) according to Berryman et al. (1982). High values of DR indicate a high dispersion of microaggregates and thus a low stability. Table 3 presents the results obtained for this analysis.

Table 3. Dispersion rate (DR) of the treatments at three depths. Lower values indicate higher stability. Average ( $\pm \mathrm{SD})$.

\begin{tabular}{cccc}
\hline \multirow{2}{*}{ Treatment } & \multicolumn{3}{c}{ Dispersion Rate $\left.\mathbf{~ g ~ g ~ g}^{-1}\right)$} \\
\cline { 2 - 4 } & $0-10 \mathrm{~cm}$ & $10-40 \mathrm{~cm}$ & $40-60 \mathrm{~cm}$ \\
\hline T1 & $0,495( \pm 0,042)$ & $0,471( \pm 0,053)$ & $0,541( \pm 0,143)$ \\
T2 & $0,475( \pm 0,080)$ & $0,509( \pm 0,091)$ & $0,586( \pm 0,125)$ \\
T3 & $0,485( \pm 0,120)$ & $0,482( \pm 0,046)$ & $0,576( \pm 0,081)$ \\
T4 & $0,482( \pm 0,035)$ & $0,524( \pm 0,060)$ & $0,498( \pm 0,062)$ \\
\hline
\end{tabular}

(There were no statistically significant differences between treatments)

For the three sampled depths there were no statistically significant differences between treatments. This is because the loamy to sandy loam textural class of soil (with a high presence of gravel increasing in depth) has a too unstable structure to have significant changes in the three-year crop rotation; besides, the roots of crops contribute with organic matter in the form of fresh residue, which generates polysaccharides as a byproduct of decomposition, so its effect on aggregate stability is important only for a short time (Kay and Angers, 2000). In this regard, Pagliai and Vignozzi (2002) mentioned that soil organic matter creates a cementing cover on the walls of the pores which has a protective function against the destructive forces of water and helps to keep the porous system functioning longer; nevertheless such protection is not permanent, because once the organic matter is decomposed and mineralized its protection decreases and the pore eventually collapses.

\section{Pore size distribution}

Although no statistically significant differences were found between treatments, some trends may be seen in Table 4.

In general, crop treatments and especially $\mathrm{T} 4$ tended to increase the drainage pores (structural porosity) in the zone of maximum rooting $(10-40 \mathrm{~cm})$ compared with the control. The lower quantity of FDP from $10-40 \mathrm{~cm}$ in T1, T2 and T3 may indicate the pre-existence of a compaction zone, given the intense trampling of the workers during pruning and harvest, which appears to be reverted by treatment $\mathrm{T} 4$. In this last case, the coarse pore system was continuous and with an increase in depth, since the roots of the rotation crops were sufficiently 
Table 4. Pore size distribution $\left(\mathrm{cm}^{3} \mathrm{~cm}^{-3}\right)$ for the treatments at three depths. Average $( \pm$ $\mathrm{SD})$.

\begin{tabular}{|c|c|c|c|c|}
\hline \multirow{2}{*}{$\begin{array}{c}\text { Pore } \\
\text { size }\end{array}$} & \multirow{2}{*}{ Treatment } & \multicolumn{3}{|c|}{ Porosity $\left(\mathrm{cm}^{3} \mathrm{~cm}^{-3}\right)$} \\
\hline & & $0-10 \mathrm{~cm}$ & $10-40 \mathrm{~cm}$ & $40-60 \mathrm{~cm}$ \\
\hline & $\mathrm{T} 1$ & $0,263( \pm 0,060)$ & $0,193( \pm 0,064)$ & $0,258( \pm 0,047)$ \\
\hline FDP & $\mathrm{T} 2$ & $0,240( \pm 0,032)$ & $0,201( \pm 0,017)$ & $0,267( \pm 0,083)$ \\
\hline \multirow[t]{3}{*}{$(>50 \mu \mathrm{m})$} & $\mathrm{T} 3$ & $0,240( \pm 0,052)$ & $0,205( \pm 0,035)$ & $0,287( \pm 0,052)$ \\
\hline & $\mathrm{T} 4$ & $0,254( \pm 0,060)$ & $0,268( \pm 0,047)$ & $0,305( \pm 0,023)$ \\
\hline & $\mathrm{T} 1$ & $0,053( \pm 0,004)$ & $0,043( \pm 0,013)$ & $0,047( \pm 0,010)$ \\
\hline SDP & $\mathrm{T} 2$ & $0,050( \pm 0,008)$ & $0,041( \pm 0,016)$ & $0,046( \pm 0,015)$ \\
\hline \multirow[t]{3}{*}{$(10-50 \mu \mathrm{m})$} & $\mathrm{T} 3$ & $0,068( \pm 0,017)$ & $0,050( \pm 0,005)$ & $0,051( \pm 0,011)$ \\
\hline & $\mathrm{T} 4$ & $0,067( \pm 0,014)$ & $0,047( \pm 0,009)$ & $0,047( \pm 0,007)$ \\
\hline & $\mathrm{T} 1$ & $0,147( \pm 0,040)$ & $0,158( \pm 0,081)$ & $0,112( \pm 0,063)$ \\
\hline WA & $\mathrm{T} 2$ & $0,158( \pm 0,043)$ & $0,169( \pm 0,018)$ & $0,144( \pm 0,095)$ \\
\hline \multirow[t]{2}{*}{$(10-0,2 \mu \mathrm{m})$} & $\mathrm{T} 3$ & $0,129( \pm 0,052)$ & $0,112( \pm 0,026)$ & $0,124( \pm 0,056)$ \\
\hline & $\mathrm{T} 4$ & $0,115( \pm 0,050)$ & $0,130( \pm 0,054)$ & $0,113( \pm 0,052)$ \\
\hline
\end{tabular}

(FDP: Fast drainage pores; SDP: Slow drainage pores; WA: Water availability. There were no statistically significant differences between treatments).

vigorous to penetrate the compacted zone. According to Pagliai and Vignozzi (2002), T4 is at the limit of being a highly porous soil in its entire profile $(25-40 \%$ of pores $>50 \mu \mathrm{m})$; however, the decrease of FDP from $10-40 \mathrm{~cm}$ in the other treatments may affect the flows of air and water in the soil.

The results of the analysis for SDP also showed no significant differences among treatments. However, in all cases there was a decrease between the first and second horizons, and the pore volume remained almost constant at the greatest depth.
Finally, the analysis of WA found no significant differences between treatments, and there was no clear tendency or differentiation between the control and the treatments. Vera and Casanova (1992) stated that the macroporosity of textural and not structural origin dominates in coarse textured soils (sandy loam to sandy); in the majority of cases there is an elevated conductivity both of air and water, which facilitates plant rooting; however, these same features tend to generate water retention problems, low adsorption capacity and poor nutrient content. 


\section{Dynamic properties of the soil}

In terms of the capacity of the soil to conduct fluids, the dynamic properties of the soil depend completely upon its inherent physical properties, such as the structure and distribution of the pore system (Benavides, 1992). However, the presence of many pores is not a guarantee of a high fluid conduction capacity, since it is the form, size, tortuosity and degree of connection that each pore has with its neighbors which determine the functionality of the soil as a conductive medium (Pagliai and Vignozzi, 2002).

\section{Air Flow}

The air flow at a given tension reflects the functionality of the pore system in relation to water content, thus the lower the tension $(-6 \mathrm{kPa})$ the wetter the soil, and therefore there are less pores available to conduct air, being only the coarsest pores useful for this function. As the soil dries (increasing water tension) more pores participate in air flow; however, their contribution is less, since the smaller pores are added. The results are shown in Figure 4.
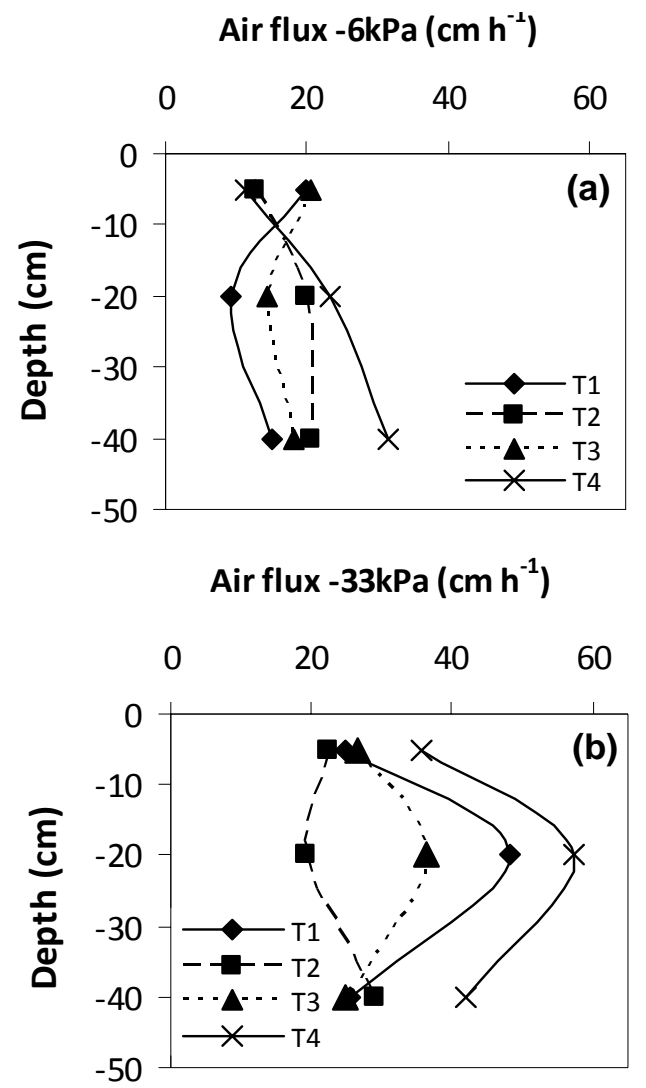

Figure 4. Air flux for each treatment, in samples equilibrated at a water suction of (a) 6 and (b) $-33 \mathrm{kPa}$ 
At $-6 \mathrm{kPa}$, treatments $\mathrm{T} 1$ and $\mathrm{T} 3$ had a greater air flow at the surface horizon compared with treatments $\mathrm{T} 2$ and $\mathrm{T} 4$; however, this situation was reversed at 20 $\mathrm{cm}$ deep, where the control showed a strong decrease due to its compaction. Treatment T4 had an important increment of air flow compared with the rest of the treatments, reaching its maximum at 40 cm depth.

The transport of gasses which allows an adequate aeration of the soil is influenced by the size and distribution of pores, their continuity within the profile and their water content (Schaeffer and Schachtschabel, 2002). These characteristics of the pore system are determined by the form in which the soil is structured; in most cases it is in the inter-aggregate spaces where the coarse pores of more than $50 \mu \mathrm{m}$ diameter are preferentially located, in contrast to what occurs with the intra-aggregate space, in which fine pores predominate (Horn, 2004). This heterogeneity in the pore size distribution determines that the majority of the processes which involve fluid transport occur in the inter-aggregate spaces, which is where the macro porosity is located.

Considering that at $-6 \mathrm{kPa}$ all the fine pores and part of the drainage pores are full of water, it is consistent to affirm that air flow in this case is due to the FDP and the larger fissures or cracks. Thus, it appears that the abrupt drop in the air conduction capacity of treatments $\mathrm{T} 1$ and T3 at $20 \mathrm{~cm}$ deep was due to the destruction of the coarse pore system due to compaction (plow pan, for example). Something similar occurred with treatments T2 and T4 on the surface, where it is clear that a compression phenomenon destroyed part of the coarse pore system, generating a degree of discontinuity.
Comparing the curves of Figures $4 \mathrm{a}$ and $4 \mathrm{~b}$, there was an important increase in air flow in treatment $\mathrm{T} 4$, which confirms the continuity of the pore system (Table 4) necessary for the renovation of the air in the soil (Dexter, 2002). Treatments T1 and T3 tended to have larger coarse pores at the surface (closer to fissures) than T2 and T4. However, the behavior of T4 at the surface suggests that, although its drainage pores are not large enough to transport more air than $\mathrm{T} 1$ and $\mathrm{T} 3$ at $6 \mathrm{kPa}$ suction, they are really more abundant and continuous, since this treatment had greater air flow at $-33 \mathrm{kPa}$.

\section{Water Flow}

The curves of accumulated infiltration (AI) indicate the capacity of the soil to conduct and store a given quantity of water (measured as a height) over time. The curves of infiltration rate (IR) represent the velocity at which this water volume is transported through the profile. The results of these measurements for the treatments are given in Figure 5.

According to the results, treatment T4 showed a statistically significant difference from the rest of the treatments; it had an important increase in its capacity to conduct water compared with the control (Figure 5a). This result contrasts for those of $\mathrm{T} 2$ and $\mathrm{T} 3$, which were similar to the control. As a consequence, the curves of Figure $5 \mathrm{~b}$ indicate that the infiltration velocity of T4 was the greatest of the four treatments. This implies that in this treatment water tended to drain through the profile very quickly, reflecting a coarse pore system which is abundant and continuous in the profile. Given the field conditions, this phenomenon may not be desirable, since, although it allows salts to be washed efficiently, the majority of the 

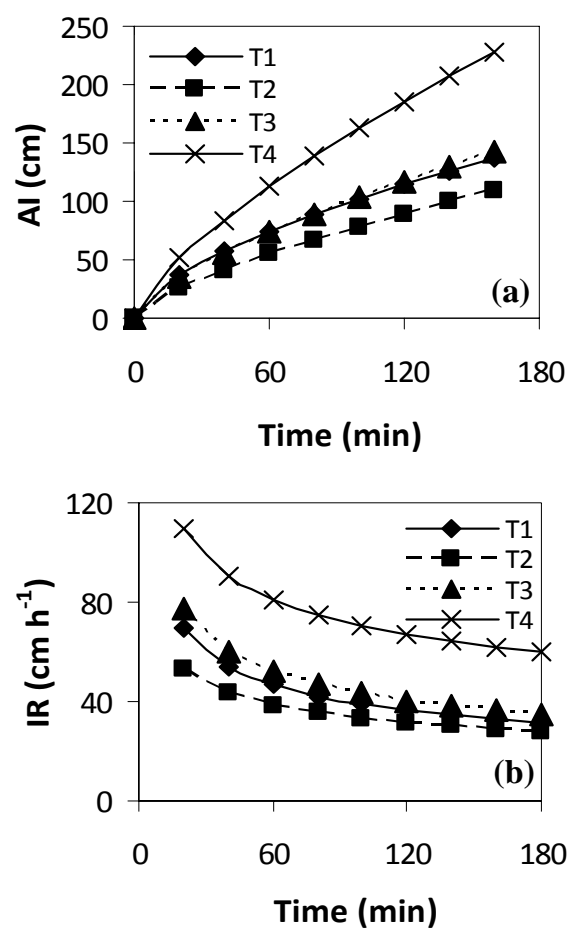

Figure 5. Curves of (a) accumulated infiltration (AI) and (b) infiltration rate (IR).

nutrients and fertilizers applied to the soil would be washed away and lixiviated by this volume of water which drains quickly.

\section{Evaluation of growth and yield of the vines}

We estimated the yield of commercial fruit and the pruning mass of the two central plants of each plot; the results are given in Table 5.

There were no significant differences among treatments for either variable, which indicates that the rotations of crops on the ridge did not interfere with the normal development of the grapes.

Table 5. Yield of fruit and pruning weight of table grape var. Thompson Seedless. Average ( \pm SD).

\begin{tabular}{|c|c|c|}
\hline Treatment & $\begin{array}{c}\text { Yield } \\
\left(\mathrm{kg} \mathrm{plant} \mathrm{p}^{-1}\right)\end{array}$ & $\begin{array}{c}\text { Pruning } \\
\text { weight } \\
\left(\mathrm{kg} \mathrm{plant}^{-1}\right)\end{array}$ \\
\hline $\mathrm{T} 1$ & $6,49( \pm 2,82)$ & $1,23( \pm 0,05)$ \\
\hline $\mathrm{T} 2$ & $7,14( \pm 2,12)$ & $1,05( \pm 0,14)$ \\
\hline $\mathrm{T} 3$ & $5,15( \pm 0,86)$ & $0,93( \pm 0,25)$ \\
\hline $\mathrm{T} 4$ & $4,88( \pm 1,50)$ & $1,39( \pm 0,42)$ \\
\hline
\end{tabular}




\section{CONCLUSIONS}

Although we found some tendencies and relations between the treatments and the measurements, both for the soil and for the crops, we cannot conclude that the management using plant cover in the ridges of the grape plantation produced significant changes in the physical properties of the coarse matrix soil or in the productive capacity of the grape plants. This is most likely due to the characteristics of the soils of this area (low development of structure and predominance of coarse textures) which do not allow changes to be detected in a short time.

The rotation broad bean/barley/pea showed a tendency to have more homogeneous values of bulk density and pore size distribution than the other treatments, indicating some decompaction due to the crops. This rotation also had a greater capacity for air and water conduction, which implies that, in this case, the pore system was much more continuous and functional.

The systematic and coherent tendencies among the different analyses suggest that the procedures designed to modify these properties should be undertaken for longer time periods, to give the system time to consolidate and be manifested both at soil level and in the improvement of growth and potential productivity of the grape vines.

\section{ACKNOWLEGEMENTS}

The authors thank Mario Holvoet for facilitating our labors in the Fundo El Fuerte. This study was financed by project INNOVA-Chile of CORFO (05 CR11IAT-06).

\section{REFERENCES}

Benavides, C. 1992. El suelo como sistema físico. In: W. Vera (ed.). Suelos, una visión actualizada del recurso. 1a Ed. Facultad de Ciencias Agronómicas y Forestales de la Universidad de Chile. Santiago, Chile. pp: 121153.

Berryman, C., Davies, D., Evans, C., Harrod, M., Hughes, A., Skinner, R., Swain, R., Soane., D. 1982. Techniques for measuring soil physical properties. Formerly Advisory Paper $\mathrm{N}^{\circ} 18$. Reference Book 441. Ministry of Agriculture, Fisheries and Food, Swedish. 116 p.

Brady, N.C., Weil, R. R. 2000. Elements of the nature and properties of soils. Prentice Hall, Upper Saddle River, New Jersey, USA. 559 p.

Chaney, K., Swift, R. S. 1984. The influence of organic matter on aggregate stability in some British soil. J. Soil Sci. 35, 223-230.

Dexter, A. 2002. Soil structure: the key to soil function. In: M. Pagliai, R. Jones (eds.). Advances in Geoecology 35. Sustainable land management-environmental protection. A soil physical approach. IUSS. Catena Verlag. Reiskirchen. Germany. pp: 57-69.

Ellies, A., Ramírez, C., Mac Donald, R. 1993. Cambios en la porosidad de un suelo producto de su uso. Turrialba 43(1), 72-76.

Faiguembaum, H. 2003. Labranza, siembra y producción de los principales cultivos de Chile. Impresora y Editor Ograma, Santiago, Chile. 760 p.

Grossman, R.B., Reinsch, T. G. 2002. Bulk density and linear extensibility. In: J.H. Dane, G.C. Topp (eds.). Methods of soil analysis. Parth 4. Physical methods. SSSA Madison Wisconsin, USA. pp: 201-228.

Hartge, K.H., Horn, R. 1992. Die Physikalische untersuchung von Böden. Ferdinand Enke Verlag. Stuttgart, Germany. 177 p.

Horn, R., Taubner, H., Wuttke, M., Baumgartl, T. 1994. Soil physical properties related to soil structure. Soil Till. Res. 30, 187216.

Horn, R. 2004. Structure formation and its consequences on gas and water transport in unsaturated arable and forest soils. In: J. Glinsky, G. Józefaciuk, K. Stahr (eds.). Soil-Plant- 
Atmosphere aeration and environmental problems. Lublin Stuttgart. Germany. pp: 79-85.

Hudson, B. 1994. Soil organic matter and available water capacity. J. Soil Water Conservat. 49, 189-194.

Juliá, C., Montecinos, S., Maldonado, A. 2008. Características Climáticas de la Región de Atacama. In: F.A. Squeo, G. Arancio, J.R Gutiérrez (eds.). Libro Rojo de la Flora Nativa y de los Sitios Prioritarios para su Conservación: Región de Atacama. Ediciones Universitarias de La Serena. La Serena, Chile. pp: 25-42.

Kay, B.D., Angers, D.A. 2000. Soil structure. In: M.E. Sumner (ed.). Handbook of Soil Science. CRC Press, Boca Ratón, Florida, USA. pp: 229276.

Kay, B.D. 1990. Rates of change of soil structure under different cropping systems. Adv. Soil S 12, 1-52. Special Issue. B.A. Stewart (ed.). Springer-Verlag, New York, USA.

Klute, A. 1986. Water retention: Laboratory methods. In: A. Klute (ed.). Methods of soil analysis. 2nd ed. ASA and SSSA, Madison WI. v.1. pp: 635-662.

Lindstrom, M.J., Voorhees, W. B. 1994. Responses of temperate crops in North America to soil compaction. In: B.D. Soane, C. Van Ouwerker (eds). Soil compaction in crop production. New York, USA. pp: 265-286.

Lobato, A., Valenzuela, J. 2000. Zona Central In: INIA. Uva de mesa en Chile. Santiago, Chile. pp: 31-38.

MINISTERIO DE AGRICULTURA, CHILE. 1968. Estudio agrológico del valle del río Copiapó. SAG-ONU. 87 p

Oades, J.M. 1993. The role of biology in the formation, stabilization and degradation of soil structure. Geoderma 56, 377- 400.

Pagliai, M., Vignozzi, N. 2002. The soil pore system as an indicator of soil quality. In: M. Pagliai, R. Jones (eds.). Sustainable land management-environmental protection. A soil physical approach. IUSS. Adv. Geoecol. 35 Catena Verlag. Reiskirchen. Germany. pp: 71-82.

Peth, S. 2004. Bodenphysikalische Untersuchungen zur Trittbelestung von Böden bei der Rentierweidewirtschaft an borealen Wold-und subarktisch-alpinen. Tundrenstandorfen-Auswirkungen auf thermische, hydrautische und mechanische Bodeneienschaften. Schriftenreihe des Instituts für Pftanzenerhährung und Bordenkunde, ISNN:0933-680x

Reynold, W. D., Elrick, D. E., Youngs, E. G., Amoozegar, A., Booltink, H. W., Bouma, J. 2002. Saturated and field saturated water flow parameters. In: J.H. Dane, G.C. Topp (eds.) Methods of soil analysis. Parth 4. Physical methods. SSSA Madison Wisconsin, USA. pp: $797-878$

Ruiz, I. (Ed). 1996. Praderas para Chile. 2da ed. INIA, Santiago Chile. 720 p

Salgado, L. 1999. Manual de estándares técnicos y económicos para obras de drenaje. Comisión Nacional de Riego-Universidad de Concepción. Concepción, Chile. 401p.

Seguel, O., Horn, R. 2006. Structure properties and pore dynamics in aggregate beds due to wetting-drying cycles. J. Plant Nutr. Soil Sc. 169, 221-232.

Seguel, O., Garcia de Cortazar, V., Casanova, M. 2003. Variación en el tiempo de las propiedades físicas de un suelo con adición de enmiendas orgánicas. Agr. Téc. (Chile) 63(3), 277-297.

Schaeffer, F., Schachtschabel, P. 2002. Lehrbuch der Bodenkunde, 15 Ed. Spectrum Publ., Heidelberg, Germany. 593 p.

Sierra, C., Osorio, A., Césped, R. 2001. Caracterización de la salinidad de los suelos y aguas del Valle del río Copiapó. Boletín INIA Nº70. Copiapó, Chile. 32 p.

Sommer, C. 1979. Bodenverdichtung und ihre Beurteilung. Z. Kulturtech. Flurber. 20, 257268.

Sprent, J., Minchin, F. 1985. Rhizobium, nodulation and nitrogen fixation. In: R. Summerfield, E. Robert (eds.). Grain Legume Crops. London, England. pp: 115-143.

Threadgill, E.D. 1982. Residual tillage effects as determined by cone index. T. ASAE 25 (4), 859963.

Vera, W., Casanova, M. 1992. Morfología de suelos. In: W. Vera (ed.). Suelos, una visión actualizada del recurso. 1a Ed. Facultad de Ciencias Agronómicas y Forestales de la Universidad de Chile. Santiago, Chile.pp: 23-72. 